\title{
Study and Control of Photovoltaic Water Pumping System
}

\begin{abstract}
Mohamed Arbi Khlifi ${ }^{\dagger}$
Abstract - Solar photovoltaic pumping system is one of most important of renewable energy applications especially in rural areas. Besides, the control strategy for standalone solar pumping system based on induction motor and without DC/DC converter has been widely studied and discussed in the literature. This topology is of great concern due its economic issues, especially when a standard frequency converter (SFCs) with scalar control is used instead of a dedicated PV inverter. This paper proposes an external control module to generate SFCs frequency reference in order to ensure both maximum power point tracking (MPPT). We present method of modeling and control of photovoltaic pumping system based centrifugal pump controlled by new improved incremental conductance in order to optimize the price and operation of pumping system this MPPT algorithm have many advantages like can be eliminate proportional integral controller It is a low cost solution since it requires no additional power equipment. The induction motor driven pump that is powered by a solar array is controlled by the indirect field oriented control (IFOC). The effectiveness of the proposed approach is illustrated by simulations carried out under Matlab Software. The experimental results are compared with simulation results.
\end{abstract}

Keywords: Renewable energy, Photovoltaic pumping, Maximum power point tracking (MPPT), Induction motor

\section{Introduction}

In recent years, the use of photovoltaic energy has been paying more attention and it is one of the most rapidly growing and the cleanest energy sources [1-2]. The electrical energy produced by photovoltaic energy can be exploited in different ways as it is inexhaustible nature, pollution free, distributed over the earth, maintenance free and continuous cost reduction, the most important advantage is the reduction of carbon dioxide emissions [3]. Besides, drinking water supply is of vital importance for life and the human need for water is continuously growing. This need becomes crucial in rural areas and islanded sites, where it is difficult or even impossible to use classical energies. Water pumping using different form of energies has been proposed as solution for water supply. Solarthermal, wind energy and hybrid system are the most investigated forms of energy for this purpose [4-5]. Also, solar energy has recently received considerable attention in dry and sunny areas. Nowadays, it is considered as the most attractive source due to the continuously development of solar cell material [6].

Thus, for remote area and under favorite meteorological conditions, different PV pumping system configurations have been investigated. According to the literature, many topologies have been proposed. They can be classified into two main categories, according to the used motor: DC or

\footnotetext{
$\dagger$ Corresponding Author: Corresponding Author: Dept. of Electrical Engineering, Faculty of Engineering, Hail University, Research Laboratory SIME, Saudi Arabia. (me.khlifi@uoh.edu.sa)
}

Received: November 26, 2014; Accepted July 30, 2015
AC motor. Systems driven by DC motor [7-9] present high efficiency and simple control strategies. They can be also directly connected to the PV array. However, pumping systems based on these solutions are limited to low power and suffer from DC motor maintenance problems. Moreover, the possible power range is significantly larger with AC motors than with DC ones [10-12]. Pumping system equipped by $\mathrm{AC}$ motor is more attractive for its ruggedness and low cost. In [13], authors discuss AC motor, and especially IM (Induction Machine), advantages above DC machine ones, by referring to pumping systems.

Control strategies already developed for AC drives give a great opportunity to use the AC motor in PV system. For standalone applications, storage cost still represents the major economic restraint. For this reason, it is preferred to replace battery storage by hydraulic (water) storage. Despite of battery storage elimination, the system cost remains high due to the panel price. To reduce it, standalone PV pumping system control strategies insuring both PV maximum power tracking and global efficiency maximization have been proposed $[14,16]$. Since high transient performances are not required for such systems, control strategies based on open loop speed control are well adapted. In [17-19], optimized open loop controls are proposed, all of them aim to determine the stator frequency reference that meets an offline optimization criterion: maximum efficiency, PV maximum power tracking, flow rate maximization, or harmonics elimination. [20-21]

The paper is organized as follows: In the first section, we propose PV, electric and hydraulic part design methodology for a standalone PV pumping system. In the 
second section, a modeling of different element of system are established. in the third section we expose all control strategy. Simulation results obtained on $1.5 \mathrm{~kW}$ laboratory setup are discussed and show the effectiveness of the investigated solutions.

\section{Pumping System Design}

The studied system is shown on Fig. 1. It is composed of solar panels, inverter, asynchronous motor and centrifugal pump. The operation of the inverter and electric motor depend on the PV array characteristics. The PV array transforms the sunlight into a continuous electric current and voltage feeding the inverter which ensures the DC/AC conversion. The water is pumped only over sunshine periods, for this reason such system can be called "along the sun" pumping.

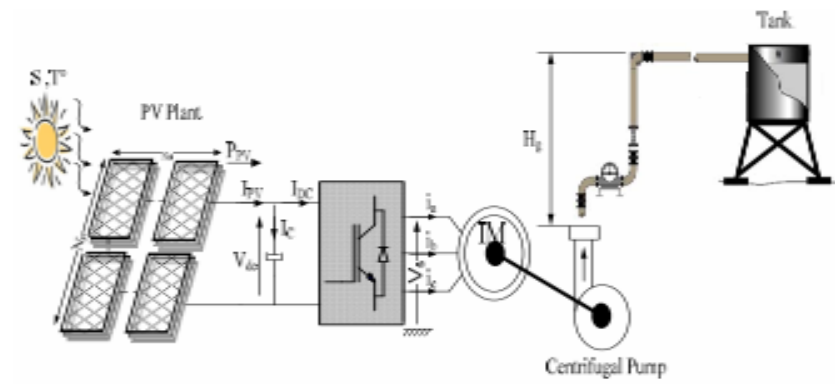

Fig. 1. PV pumping system with single stage

\section{Modeling of Different Element of System}

The power configuration of the studied photovoltaic pumping system is depicted in Fig. 2.

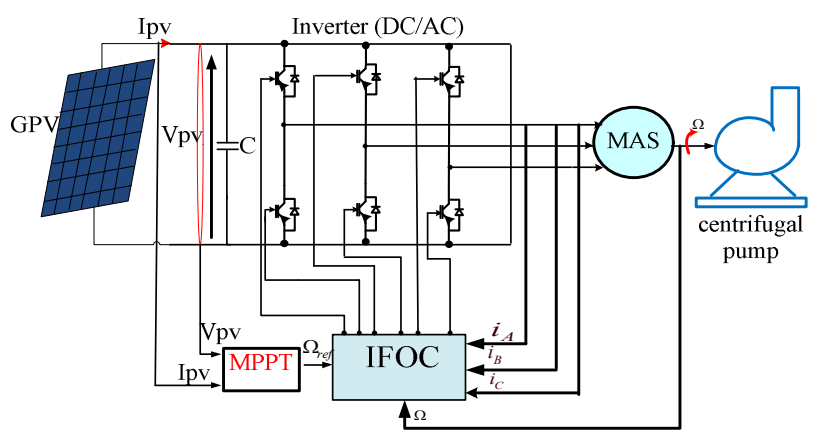

Fig.2. Bloc diagram of $P_{v}$ pumping system

\subsection{Modeling of photovoltaic array}

The Photovoltaic module used in this system is a 36 multi-crystalline solar cell in series able to provide $53.32 \mathrm{~W}$ of maximum power. A mathematical model of a solar cell can be treated as a current source parallel with a diode, the model is completed by a parallel resistor $\mathrm{R}_{\mathrm{sh}}$ and a series

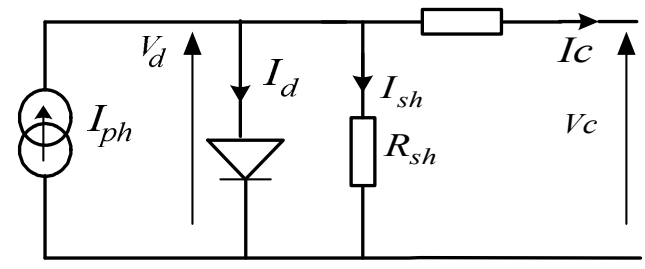

Fig. 3. Equivalent circuit of a solar cell

resistor $\mathrm{R}_{\mathrm{s}}$ as shown in Fig. 3 .

Thus, to achieve the desired current and voltage, an association of Ns modules in series and in parallel $\mathrm{N}_{p}$ connected modules gives rise to a $\mathrm{P}_{\mathrm{v}}$ generator, its output current voltage characteristic is given by (1).

$$
\begin{aligned}
& I_{p v}=N_{p} I_{p h}-N_{p} I_{0}\left(\exp \left(\frac{\frac{V_{p v}}{N_{s}}+\frac{R_{s} I_{p v}}{N_{p}}}{a V_{T}}\right)-1\right)-\left(\frac{V_{p v}+\frac{N_{s} R_{s} I_{p v}}{N_{p}}}{\frac{R_{s h} N_{s}}{N_{p}}}\right) \\
& \text { with: } \quad V_{T}=\frac{n K T}{q}
\end{aligned}
$$

\subsection{Modeling motor-pump}

Basic model of an induction machine may be given in terms of space vectors, in an arbitrary frame of reference $\omega_{a}$, with the following set of equations:

$$
\begin{gathered}
\bar{v}_{s}=R_{s} \bar{i}_{s}+\frac{d \bar{\lambda}_{s}}{d t}+j \omega_{a} \bar{\lambda}_{s} \\
\bar{v}_{r}=R_{r} \bar{i}_{r}+\frac{d \bar{\lambda}_{r}}{d t}+j\left(\omega_{a}-\omega\right) \bar{\lambda}_{r}
\end{gathered}
$$

All rotor quantities are referred to the stator. Rotor winding are usually short-circuited, then $\overline{v_{r}}=0$. In this paper, this advantage is taken from beginning so that $l_{s}=l_{r}=l$ is considered and $L_{s}=L_{r}=L$ is resulted. Stator and rotor flux linkages are:

$$
\begin{aligned}
& \bar{\lambda}_{s}=l \bar{i}_{s}+\bar{\lambda}_{m} \\
& \bar{\lambda}_{r}=l \bar{i}_{r}+\bar{\lambda}_{m}
\end{aligned}
$$

and:

$$
\begin{aligned}
& \bar{\lambda}_{m}=L_{m} \bar{i}_{m} \\
& \overline{i_{m}}=\overline{i_{s}}+\bar{i}_{r}
\end{aligned}
$$

The choice of a pair of currents, for example $\left(\overline{i_{s}}, \overline{i_{r}}\right)$, among the three possible ones, imposes the description of fluxes $\overline{\lambda_{s}}$ and $\bar{\lambda}_{r}$ as well as their derivatives in terms of the selected vectors. After necessary manipulations, the main differential system can be represented by: 


$$
[V]=[A][\dot{X}]+[B][X] \text { with: }
$$

$$
\begin{gathered}
{[V]=\left[\begin{array}{llll}
v_{d s} & v_{q s} & 0
\end{array}\right]^{t}} \\
{[X]=\left[\begin{array}{llll}
i_{d s} & i_{q s} & i_{d r} & i_{q r}
\end{array}\right]^{t}} \\
{[A]=\left[\begin{array}{cccc}
l_{s}+L_{m} & 0 & L_{m} & L_{0} \\
0 & l_{s}+L_{q} & 0 & L_{m} \\
L_{m} & 0 & l_{r}+L_{m} & 0 \\
0 & L_{m} & 0 & l_{r}+L_{m}
\end{array}\right]} \\
{[B]=\left[\begin{array}{cccc}
R_{s} & -w_{a} L_{s} & 0 & -w_{a} L_{m} \\
w_{a} L_{s} & R_{s} & w_{a} L_{m} & 0 \\
0 & -w L_{m} & R_{r} & -w L_{r} \\
w^{\prime} L_{m} & 0 & w L_{r} & R_{r}
\end{array}\right]}
\end{gathered}
$$

The electromagnetic torque produced can be expressed by:

$$
C e m=\frac{3}{2} \frac{p M}{L_{r}}\left(\phi_{r d} i_{s q}-\phi_{r q} i_{s d}\right)
$$

Assuming ideal power switches, the output voltage $\left(\mathrm{V}_{\mathrm{A}}\right.$, $\mathrm{V}_{\mathrm{B}}, \mathrm{V}_{\mathrm{C}}$ ) of the inverter is given by:

$$
\left[\begin{array}{l}
V_{A} \\
V_{B} \\
V_{C}
\end{array}\right]=\frac{V_{p}}{3}\left[\begin{array}{ccc}
2 & -1 & -1 \\
-1 & 2 & -1 \\
-1 & -1 & 2
\end{array}\right]\left[\begin{array}{l}
C_{1} \\
C_{2} \\
C_{3}
\end{array}\right]
$$

Where $\mathrm{C} 1, \mathrm{C} 2, \mathrm{C} 3$ are the controller signals applied to the switches and $\mathrm{Vpv}$ was the array voltage. The water pump chosen is a centrifugal pump applies a load torque proportional to the square of the rotor speed. $C_{r}=K \Omega^{2}$

\section{Control System}

The photovoltaic array is regulated at the optimum power point that it can provide to obtain best performance from the system.

\subsection{MPPT Control algorithm}

The aim of the maximum power point tracking is to extract the maximum output power, The MPPT used in this paper based on two algorithms that are perturb and observe algorithm and Incremental conductance.

\subsubsection{Perturb and observe}

Perturb and observe algorithm is very popular and widely used in control of MPPT because of its law-cost, simplicity and ease of implementation. The MPPT is continuously subjected to two excitation source, the first

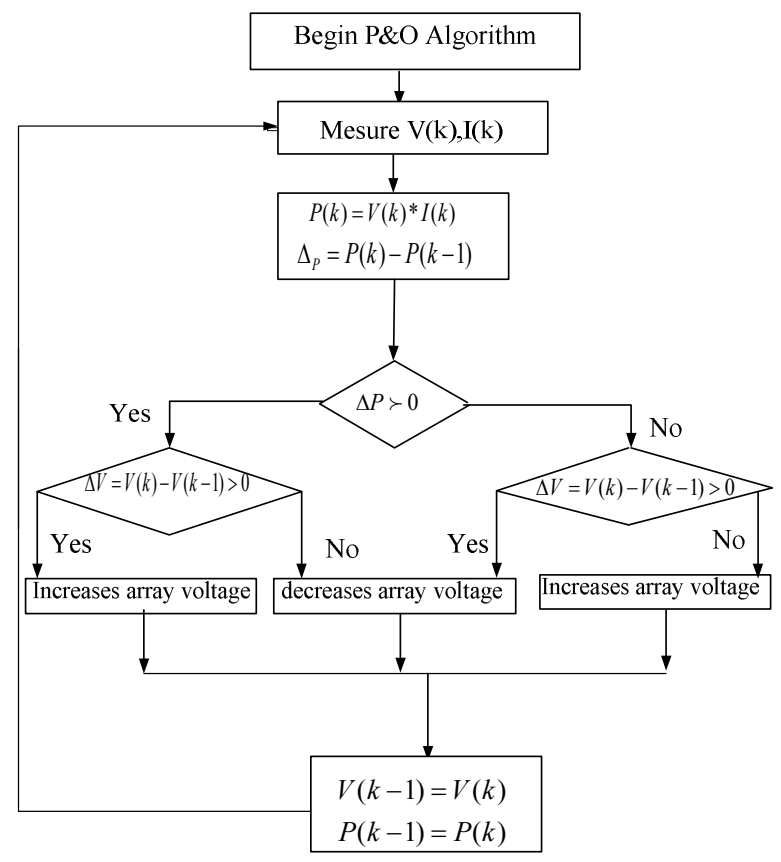

Fig. 4. Flowchart for $\mathrm{P} \& \mathrm{O}$

originating from the weather condition and the other from the perturbation of the tracking algorithm. Basically, it is based on the following criterion: the module voltage is perturbed by a small increment, and the resulting change in the power is observed. If the change in power is positive, the voltage is adjusted by the same increment, and the power is again observed. This continues until the change in power is negative, at which point the direction of the change in voltage is reversed. Fig. 4 shows the flowchart that corresponds to the $\mathrm{P} \& \mathrm{O}$ implemented algorithm.

\subsubsection{Incremental conduction algorithm}

The Incremental Conductance method offers good performance under rapidly changing atmospheric conditions. The derivative of output power $\mathrm{P}$ with respective to panel voltage $V_{p v}$ is equal to zero at Maximum Power Point (MPP). The slope of the PV array power curve is zero at the MPP, increasing on the left of the MPP. and decreasing on the right-hand side of the MPP. The basic equations of this method are as follows.

$$
\begin{cases}\frac{d I_{p v}}{d V_{p v}}=-\frac{I_{p v}}{V_{p v}} & \text { for } V=V_{m p} \\ \frac{d I_{p v}}{d V_{p v}}>-\frac{I_{p v}}{V_{p v}} & \text { for } V<V_{m p} \\ \frac{d I_{p v}}{d V_{p v}}<-\frac{I_{p v}}{V_{p v}} & \text { for } V>V_{m p}\end{cases}
$$

Fig. 5 shows the flowchart that corresponds to the IC implemented algorithm. 


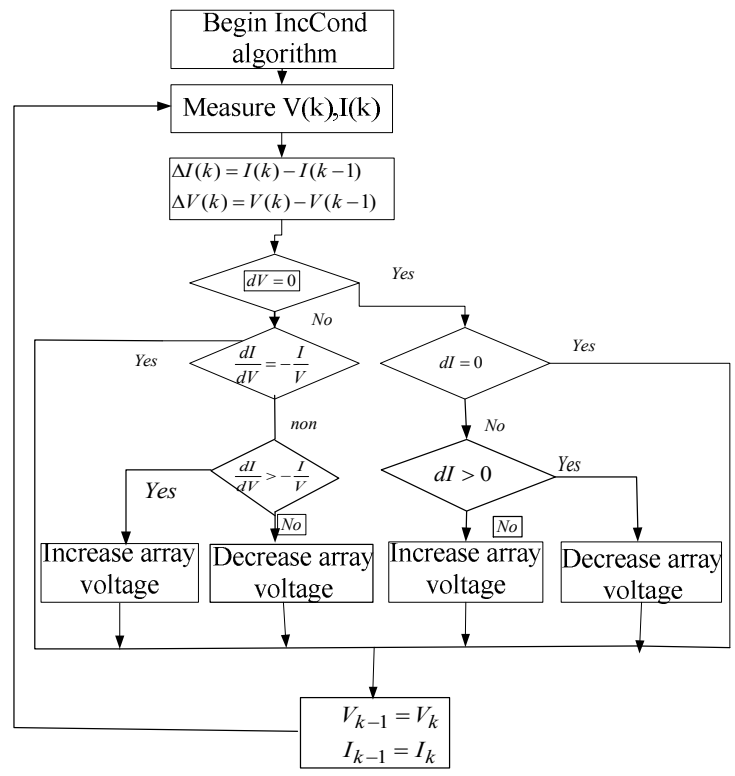

Fig. 5. Flowchart of the IC method

The disadvantage of this algorithm is increased complexity compared to perturb and observe algorithm.

\subsection{IFOC control of the induction machine}

The indirect field oriented control (IFOC) control ensures the decoupling between the flux and the torque in order to control the rotor flux, the speed and the two stator currents. The electromagnetic torque becomes proportional to the stator quadrature current as a similar to a DC machine. The field oriented control is obtained by (16).

$$
\left\{\begin{array}{c}
\phi_{d r}=\phi_{r} \\
\phi_{q r}=0
\end{array}\right.
$$

Thus the Eqs. (11) (12) and (16) become:

$$
\left\{\begin{array}{l}
\frac{d i_{d s}}{d t}=\frac{1}{\sigma L_{s}}\left(-R_{s} i_{d s}-w_{s} \sigma L_{s} i_{q s}+\frac{M}{L_{r}} \frac{d \phi_{r}}{d t}+V_{d s}\right) \\
\frac{d i_{q s}}{d t}=\frac{1}{\sigma L_{s}}\left(-R_{s} i_{q s}-w_{s} \sigma L_{s} i_{d s}-\frac{M}{L_{r}} w_{s} \phi_{r}+V_{q s}\right) \\
\frac{d \phi_{r}}{d t}=\frac{M}{\tau_{r}} i_{d s}-\frac{1}{\tau_{r}} \varphi_{r} \\
w_{s}=\frac{M}{\tau_{r}} \frac{i_{q s}}{\phi_{r}}+p \Omega \\
\text { Cem }=\frac{3 p M}{2 L_{r}} \phi_{r} i q s
\end{array}\right.
$$

\section{Experimental Results and Discussion}

To prove the feasibility of the proposed control strategy, a set of experiments has been conducted in different operating conditions. First, test results corresponding to normal operation have been analyzed to carry out nominal performance characteristics. Moreover, the MPPT algorithm has been reported. Subsequently, the effect of variation of the MPPT algorithm has been evaluated in terms of MPPT efficiency. Finally, the indirect field oriented control (IFOC) of the induction has been considered. The experimental test has been conducted by considering a sudden change of irradiation on a PV panel due to a fast partial shading effect, thus highlighting the effectiveness of the proposed distributed power conversion approach. For the experiments, a PV module have been adopted. Moreover, a I-V tracer has also been used to extract data concerning PV panel characteristics.

\subsection{Experimental nominal performance characteristics}

The PV cells and the attached load (i.e., a induction motor (IM) and a pump installed in a hydraulic piping system) are characterized by their current voltage relation (I-V curve). The power output, $\mathrm{P}$, is the product of the current, I, and the voltage, V. Fig. 6. shows the I-V and Fig. 7. P-V curves of a PV module made in nominal configuration of Specification of cell module SM55 at STC (measured at a solar radiation of $1000 \mathrm{~W} / \mathrm{m}^{2}$ and a cell temperature of $25^{\circ} \mathrm{C}$ ) along with the I-V curve of a load comprising of a IM coupled to a centrifugal pump that move water in a hydraulic piping system.

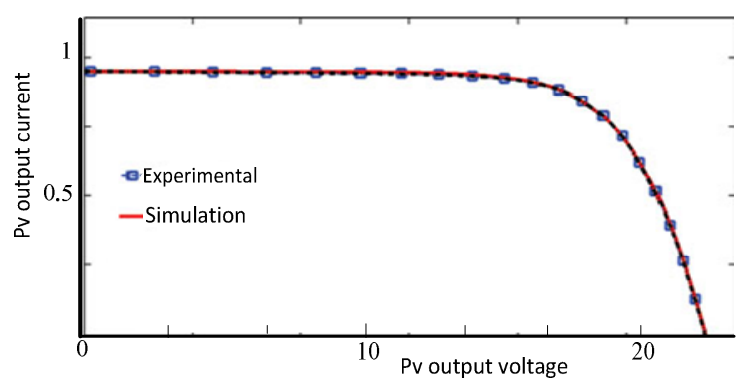

Fig. 6. The I-V curves of a PV module of a IM motor coupled to a centrifugal pump along with the PV system

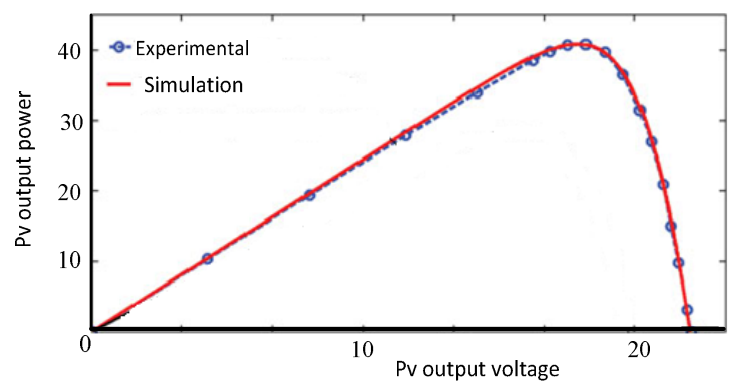

Fig. 7. The P-V curves of a PV module of a IM motor coupled to a centrifugal pump along 


\subsection{MPPT algorithm control}

The simulation result obtained of the proposed control technique applied to the photovoltaic pumping system using parameters given in Appendix are the following. Figs. 8,9 presents the evolution of Power voltage and current voltage characteristic by $\mathrm{P} \& \mathrm{O}$ algorithm during a variation transient in solar radiation, the irradiation varies from $200 \mathrm{~W} / \mathrm{m}^{2}$ to $1000 \mathrm{w} / \mathrm{m}^{2}$ assuming constant temperature $298 \mathrm{~K}$. It can be seen that the increase of the illumination explained by an increase of the maximum power available and the system track the new maximum power point tracking very quickly when the weather change suddenly but the operating point oscillates around The MPP, resulting loss in power system. These oscillations would reduce the effectiveness of the photovoltaic power.

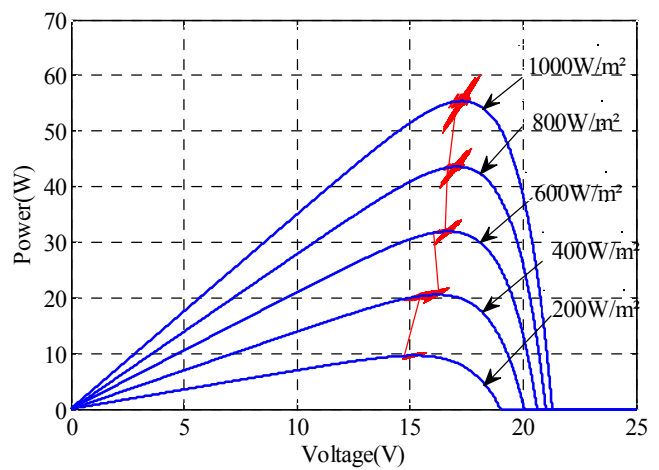

Fig. 8. Power-Voltage characteristics

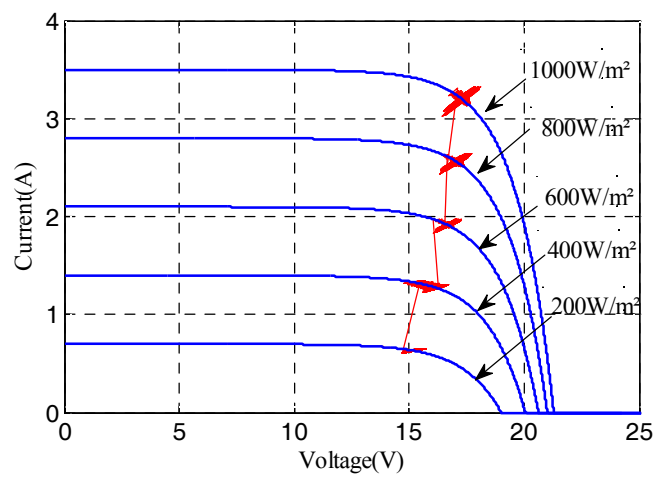

Fig. 9. Current-Voltage characteristics

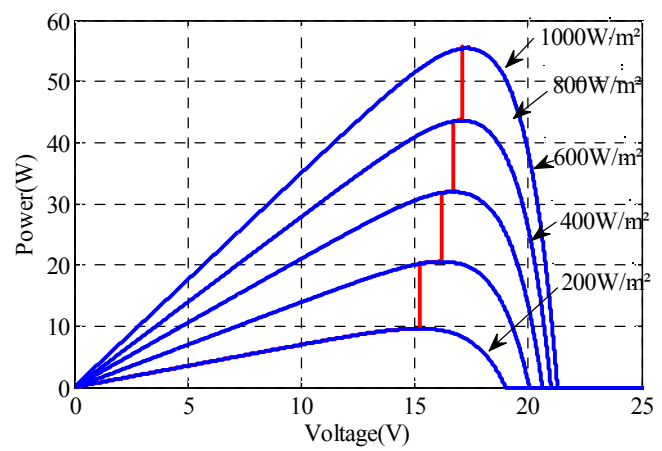

Fig.10. Power-Voltage characteristics

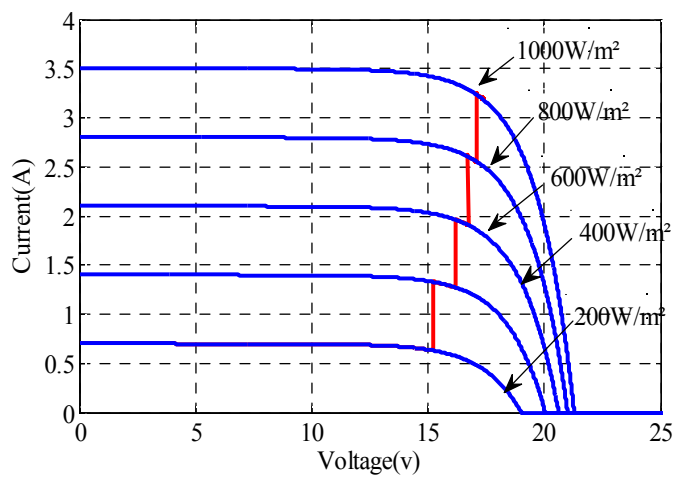

Fig.11. Current-Voltage characteristics

\subsubsection{Pv panel simulation with $P \& O$ controller}

Fig. 10, Fig. 11 shows the IC algorithm efficiencies that the MPPT has reached without perturb the operating point from begin to end of the simulation.

\subsubsection{Pv panel simulation with IC controller}

Comparison of $\mathrm{P} \& \mathrm{O}$ controller and IC, in this system shows that incremental conductance given better results than perturb and observe, it improved stability and offered higher energy utilization efficiencies compared to $\mathrm{P} \& \mathrm{O}$ algorithm, The MPPT without oscillations is desirable, for this reason we choose using the IC employed in our standalone $\mathrm{P}_{\mathrm{v}}$ pumping system to further reduce the power loss.

\subsection{Pumping photovoltaic simulation}

Initially, we considered a fixed illumination ( $E=1000$ $\mathrm{W} / \mathrm{m}^{2}$ ) and a variable temperature Fig. 12 to see its impact on the power generator photovoltaic. Then we can show a good convergence of the power generator $P_{v}$ to its optimum value.

\subsubsection{Variation of the temperature value $T$}
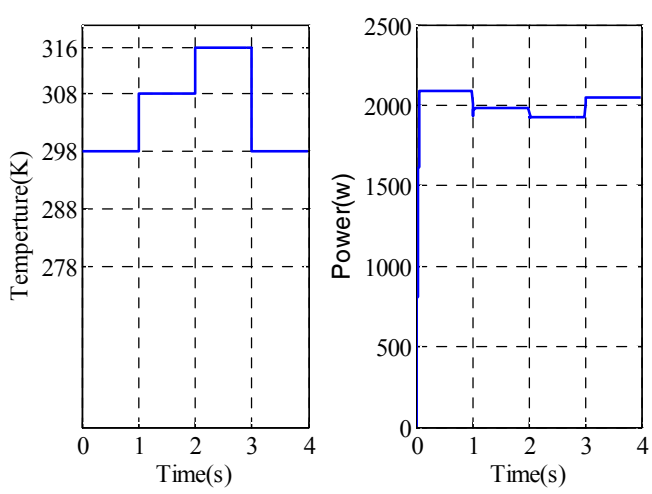

Fig. 12. Profile of the Temperature and the power produced by $\mathrm{G}_{\mathrm{Pv}}$ 


\subsubsection{Variation of the solar illumination value $E$}

In order to test the continuation of the $\mathrm{P}_{\max }$, we choose to vary the solar illumination value $\mathrm{E}$ as it is shown in Fig. 13, and to see its impact on the performances of the photovoltaic pumping.

The simulation results Fig. 14 showed the excellent performance of the control in response to serve change in temperature and solar intensity condition. The output power of the generator photovoltaic system was substantially change with the weather condition.

Fig.15, Fig.16 and Fig. 17 illustrates the pump flow, the waveform of the mechanical speed $(\mathrm{N})$, and the electromagnetic torque wave form of the induction motor, there are a small transitory on the tracking to their reference which are stabilize at their reference value during a time of $0.1 \mathrm{~s}$ and closed to their optimal value for different

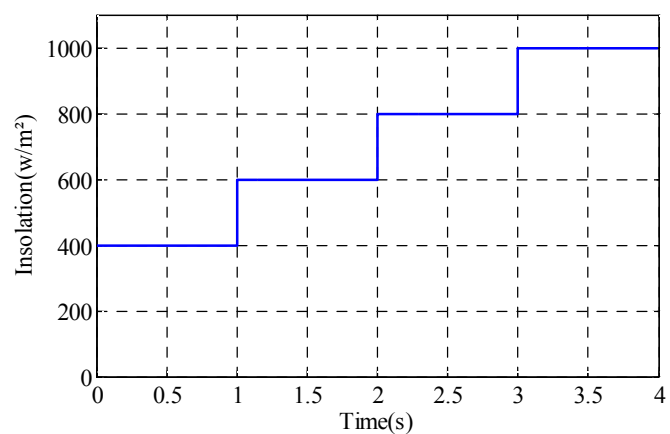

Fig.13. Variation in solar radiation

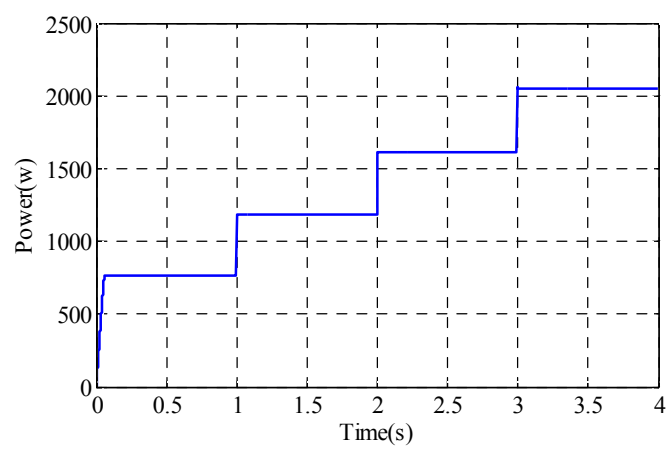

Fig.14. $P_{v}$ array power for sudden increase in illumination

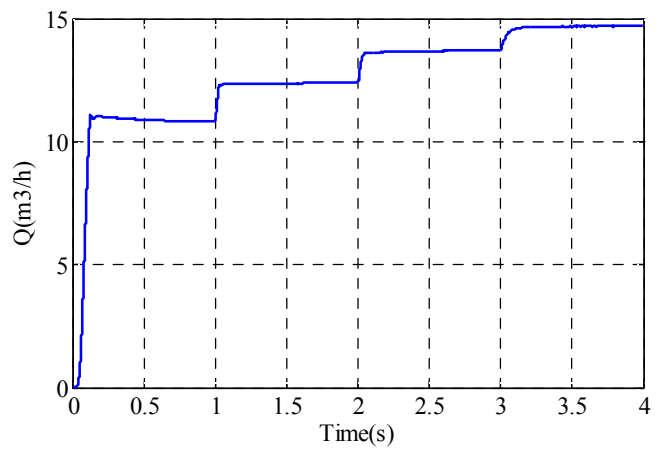

Fig. 15. Evolution of the pump flow

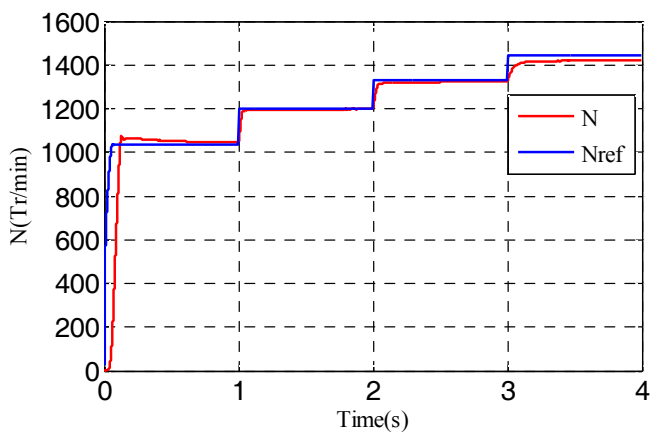

Fig. 16. Evolution of the mechanical speed

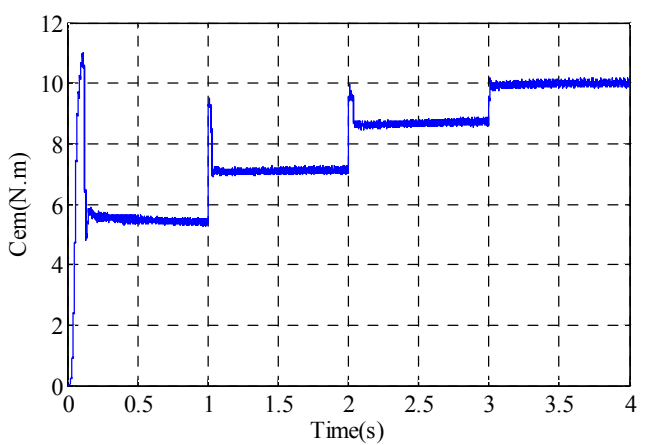

Fig. 17. Evolution of the torque

value of insulation.

\section{Conclusion}

The proposed system was simulated, we introduced an approach of modeling and control of a photovoltaic pumping system. From the results acquired during the simulations, we show clearly the benefits of the MPPT algorithm which can significantly increase the efficiency of energy production and assure better tracking performance under different weather condition. Results presented in this paper demonstrate that the proposed system has a faster response to transient temperature and irradiation. Control and analysis of hybrid system will follow in future work. The I-V and P-V characteristics are found to be compatible with the corresponding experimental/measured data. Numerical results confirm the acceptable performance of the proposed method in terms of the solution quality for all reported test scenarios compared to other methods in the literature.

\section{References}

M. Chergui, M. Bourahla, "Contribution to Improve the Direct Torque Control in the Photovoltaic pumping", IEEE Conference on Developments in Esystems Engineering (DESE), pp. 602-607, 2011. 
S.K. Kollimalla, M.K. Mishra, "Adaptive Perturb \& Observe MPPT Algorithm for Photovoltaic System", IEEE on Power and Energy Conference at Illinois (PECI), pp. 42-47, 2013.

A. Khiareddine, C. Ben Salah, M.F. Mimouni, "Determination of the target speed corresponding to the optimum functioning of a photovoltaic system pumping and regulation of the water level", International Conference on Electrical Engineering and Software Applications (ICEESA), pp. 1-5, 2013.

V. Vongmanee, "The Photovoltaic Water Pumping System Using Optimum Slip Control to Maximum Power and Efficiency", IEEE Conference on power tech, pp. $1-5,2005$.

A.O. Taufik, M. Anwari, M. Taufik, "Modeling and Simulation of Photovoltaic Water Pumping System", Third Asia International Conference on Modeling \& Simulation, pp. 497-502, 2009.

A. Acakpovi, F.F. Xavier, R. Awuah-Baffour, "Analy-tical method of sizing photovoltaic water pumping system", International Conference on Adaptive Science \& Technology (ICAST), pp. 65-69, 2012.

D. Sera, L. Mathe, T. Kerekes, S.V. Spataru, R. Teodorescu, "On the Perturb-and-Observe and Incre-mental Conductance MPPT Methods for PV Systems", IEEE Journal of Photovoltaics, Vol. 3, No.3, pp. 10701078, 2013.

N.N. Singh, S.P. Singh, D. Singh, B. Singh, R.P. Vishvakarma, "An Efficient Control on Photovoltaic Energy Conversion System Using Modified Perturb and Observe Technique for Stand Alone Applications", IEEE Student's Conf. on Electrical, Electronics and Computer Science (SCEECS), pp.1-4, 2012.

S.G. Malla, C.N. Bhende ,S. Mishra, "Photovoltaic based Water Pumping System", IEEE Conference on Energy, Automation, and Signal (ICEAS), pp.1-4, 2011.

Jacob James Nedumgatt, K.B. Jayakrishnan, S. Umashankar, D. Vijayakumar, D.P. Kothari "Perturb and Observe MPPT Algorithm for Solar PV SystemsModeling and Simulation", IEEE On India Conference (INDICON), pp.1-6, 2011.

M. Khelif, A. M'raoui, A.Malek, "Simulation, optimization and performance analysis of an analog, easy to implement, perturb and observe MPPT technique to be used in a $1.5 \mathrm{KWp}$ photovoltaic system, IEEE on Renewable and Sustainable Energy Conference (IRSEC), pp.10-17, 2013.

F.Z. Amatoul, M.T. Lamchich, A. Outzourhit, "Design Control of DC/AC Converter for a grid Connected PV Systems using Matlab/Simulink", IEEE Conference on Multimedia Computing and Systems (ICMCS) , pp.1-7, 2011.

L. Piegari, R. Rizzo , "Adaptive perturb and observe algorithm for photovoltaic maximum power point tracking”, IET journals \& magazines on Renewable
Power Generation, Vol.4, No.4, pp. 317-328, 2010.

S.Bal, B. C.Babu, "Comparative Study between P\&O and Current Compensation Method for MPPT of PV Energy System" IEEE Conference on Engineering and Systems (SCES), pp.1-6, 2012.

J. Chauhan, P. Chauhan, T. Maniar, A. Joshi, “com-parison of MPPT Algorithms for DC-DC Converters Based Photovoltaic Systems", IEEE Conference on Energy Efficient Technologies for Sustainability (ICEETS), pp. 476-481, 2013.

R.Roshan, Y.Yadav, S.Umashankar, D.Vijayakumar, D.P. Kothari, "Modeling and Simulation of Incre-mental Conductance MPPT Algorithm Based Solar Photo Voltaic System using CUK Converter", IEEE Conference on Energy Efficient Technologies for Sustainability (ICEETS), pp. 584-589, 2013.

A. Safari, S. Mekhilef, "Simulation and Hardware Implementation of Incremental Conductance MPPT with Direct Control Method Using Cuk Converter", IEEE Transaction on Industrial Electronics, Vol. 58, No. 4, pp. 1154-1161, 2011.

Yang, Y., and Blaabjerg, F., "Low-voltage ride-through capability of a single-stage single-phase photovoltaic system connected to the low-voltage grid," Int. J. Photoenergy, Vol. 2013, pp. 1-9, 2013.

Carrasco, J. E., Tena, J. M., Ugena, D., Alonso-Martinez, J., Santos-Martin, D., and Arnaltes, S., "Testing low voltage ride through capabilities of solar inverters," Electr. Power Syst. Res., Vol. 96, pp. 111-118, 2013.

Xiao, W., Edwin, F. F., Spaguolo, G., and Jatskevich, J., "Efficient approaches for modeling and simulating photovoltaic power systems," IEEE J. Photovoltaics, Vol.. 3, No. 1, pp. 500-508, January 2013.

Mohammed A. Elgendy, Bashar Zahawi, David J. Atkinson, "Assessment of Perturb and Observe MPPT Algorithm Implementation Techniques for PV Pumping Applications", IEEE Transactions on Sustainable Energy, Vol. 3, No. 1, 2012.

\section{Appendix}

Table1. Induction motor parameters

\begin{tabular}{c|c}
\hline $\mathrm{Rs}=5.72 \Omega \mathrm{Rr}=4.2 \Omega$ & $\mathrm{Ls}=\mathrm{Lr}=0.462 \mathrm{H}, \mathrm{M}=0.44 \mathrm{H}$ \\
\hline $\mathrm{J}=0.0049 \mathrm{Kg} \cdot \mathrm{m}^{2}$ & $\mathrm{f}=1.5 .10-4 \mathrm{Nm} / \mathrm{rads}-1$ \\
\hline $\mathrm{P}=2$ & $\mathrm{P}=1.5 \mathrm{Kw}, \mathrm{N}=1450 \mathrm{tr} / \mathrm{min}$ \\
\hline
\end{tabular}

Table 2. Specification of PV module SM55 at STC ( $=$ $1000 \mathrm{~W} / \mathrm{m}^{2}, \mathrm{~T}=25^{\circ} \mathrm{C}$ )

\begin{tabular}{c|c|c}
\hline Parameters & Symbol & Value \\
\hline Voltage at maximum power & $\mathrm{V}_{\mathrm{MPP}}$ & $17.2 \mathrm{~V}$ \\
\hline Current at maximum power & $\mathrm{I}_{\mathrm{MPP}}$ & $3.1 \mathrm{~A}$ \\
\hline Open circuit voltage & $\mathrm{V}_{\mathrm{OC}}$ & $21.6 \mathrm{~V}$ \\
\hline Short circuit Current & $\mathrm{I}_{\mathrm{sc}}$ & $3.5 \mathrm{~A}$ \\
\hline
\end{tabular}

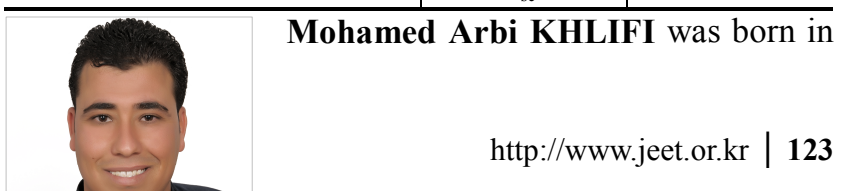


Tunisia, in 1982. He received the M.S., and Ph.D. in Electrical Engineering from the University of Tunis, Tunisia. He joined the National college of Engineering of Tunis, as Assistant Pro-fessor in the Department of Electrical Engineering. He is currently a Professor in the Electrical Engineering Department, College of Engineering, Hail University. Dr. KHLIFI has published More than 50 research papers in many journals and international conferences. He has organized many national and international conferences and has been member of the international Board committee of many International Conferences, MELECON2012, ICESA2013, IREC2014. His is Associate Editor of IJECEE journal. His main is member IEEE FRANCE section and ASET (association for Tunisian electrical specialists). He is research laboratory in Signal Image and Energy Mastery in the University of Tunis. His main interest research areas are renewable energy, wind power and solar in smart grid, and control of high efficiency integrated electric energy conversion in various industrial fields. Power electronics and control, which include electrical machine drives. 